\title{
Blue Nevus
}

National Cancer Institute

\section{Source}

National Cancer Institute. Blue Nevus. NCI Thesaurus. Code C3803.

An intradermal nevus characterized by the presence of benign pigmented dendritic spindle-shaped melanocytes. It most frequently occurs in the skin of the distal upper extremities, followed by the lower extremities, scalp, face, and buttocks. It usually presents as a single blue or blue-black papular lesion less than $1 \mathrm{~cm}$ in diameter. Simple excision is usually curative. 